Article

\title{
Leading Teaching during a Pandemic in Higher Education-A Case Study in a Finnish University
}

\author{
Anna Parpala ${ }^{1, *(D)}$ and Susanna Niinistö-Sivuranta ${ }^{2}$ \\ 1 Centre for University Teaching and Learning, University of Helsinki, 00100 Helsinki, Finland \\ 2 University Services (Teaching and Learning), University of Helsinki, 00100 Helsinki, Finland \\ susanna.niinisto-sivuranta@helsinki.fi \\ * Correspondence: anna.parpala@helsinki.fi
}

Citation: Parpala, A.;

Niinistö-Sivuranta, S. Leading

Teaching during a Pandemic in

Higher Education-A Case Study in

a Finnish University. Educ. Sci. 2022,

12, 147. https://doi.org/10.3390/

educsci12030147

Academic Editor: Han Reichgelt

Received: 28 January 2022

Accepted: 16 February 2022

Published: 22 February 2022

Publisher's Note: MDPI stays neutral with regard to jurisdictional claims in published maps and institutional affiliations.

Copyright: (C) 2022 by the authors. Licensee MDPI, Basel, Switzerland. This article is an open access article distributed under the terms and conditions of the Creative Commons Attribution (CC BY) license (https:// creativecommons.org/licenses/by/ $4.0 /)$.

\begin{abstract}
Many studies have shown that the shift from contact teaching to fully online teaching has had many negative effects on teaching and learning during the COVID-19 pandemic. Although the pandemic has also had an effect on leading teaching in higher education institutions, there has not been much empirical research on leaders' experiences during a pandemic. The present study brings out the voices of academic leaders themselves and how they experienced the pandemic in the light of leading teaching that is provided exclusively online. To examine the variety of degree programme directors' experiences, open-ended questions were asked and analysed using content analysis. Seven dimensions of experiences were detected, and they represented negative, positive and neutral experiences. The present study shows that higher education leaders need more guidance, training and support to face crisis situations and develop their skills, especially to communicate effectively, but at the same time to do so collaboratively and in an informal way.
\end{abstract}

Keywords: leadership; higher education; COVID-19; pandemic; crisis management

\section{Introduction}

Higher education institutions have been facing historically challenging times during the COVID-19 pandemic when all teaching and learning has been carried out online [1]. Studies have shown that the shift from contact teaching to fully online teaching has had a negative effect on students' mental well-being [2], engagement in studies [3,4] and sense of loneliness [5]. Moreover, there have been many challenges in higher education teaching. For example, there has been a variety of teacher approaches towards the use of online teaching methods, from resistance to active and thoughtful use of new methods [6]. Teachers also varied in their degree of readiness for online teaching [7] and their emotions towards online teaching [8]. In addition, the teaching environment (technology infrastructure, support for the use of online tools) has been a crucial element in how teachers have been able to cope with online teaching [6]. However, at the same time, both students and teachers have been experiencing positively the flexible online learning environment and students' academic achievement has even improved through online learning $[9,10]$. To sum up, the pandemic has had multiple effects on teaching and learning, and research has mainly focused on the perspective of teachers and students [2-13].

The complex situation of the pandemic has also had a huge effect on educational management. As leaders in educational institutions have an important role in ensuring that both teaching and learning are proceeding smoothly [14,15], it is very important to examine what effect the pandemic has had on leading teaching in higher education. Moreover, the swift transition from contact teaching to online teaching has required new leadership skills which had not been necessary in the culture of contact, face-to-face teaching. For example, leaders had no time for planning and discussions, as online teaching and learning needed to be established quickly with good quality and minimum expense [16]. They needed to 
be goal- and future-oriented in a situation in which no-one knew what would happen next [17]. Although the pandemic has also had an effect on leading teaching in higher education institutions, there has been little empirical research on leaders' experiences during a pandemic. Therefore, it is important to examine how leaders managed and what impact this pandemic had, especially on leading teaching. Through this research we have learnt how to support leaders in similar, exceptional situations.

\subsection{Leading Teaching during Pandemic}

There are many ways to become an academic leader [18]. Some academic leaders are selected for the position whereas some have just drifted into it. There might even be situations in which leaders have taken the position only because no applicants had been interested in it. The position is challenging as the tasks include a range of fragmented and challenging activities, including assessment of learning, curriculum planning, scheduling the courses, budget work, coordination and co-operation duties, etc. [19]. Moreover, the leaders often do not have enough training and support for taking care of these activities [20]. Previous research has long shown that the role of academic leader is stressful and is rarely rewarding for academics [21,22]. In light of these previous findings, the pandemic increased the number of already challenging leading tasks and made them even more complicated [23]. Leaders needed to be future-focused, responsive, emphasise values and take moral issues into account in leading academics [24]. In their critical examination, Marshall and his colleagues [25] suggested that during the pandemic, the academic leaders need the ability to provide clear direction, communicate effectively, work collaboratively and engage in adaptive leadership. Gurr and Drysdale [17] emphasise that especially the ability to provide clear direction and risk consideration are the most important elements of educational leadership in crisis situations.

\subsection{Aim of the Study}

This study brings out the voices of academic leaders and how they experienced the pandemic, and especially how they led online teaching. The aim was to detect the variety of how the academic leaders experienced the leading of teaching and learning during a pandemic in higher education.

\section{Materials and Methods}

\subsection{Participants and Instrument}

The data were collected during Spring 2021 through an electronic questionnaire sent to degree programme directors in a large Finnish research-oriented university. Degree programme leaders are responsible for assuring the quality of teaching and learning at the university. Moreover, their duties involve, for example, curriculum planning, budget work and collaboration, but leading teaching can be considered to be their main task. Out of 96 degree programme directors, 28 voluntarily responded to the questionnaire. In the openended questions, the directors were asked to answer a question concerning the pandemic and leading teaching during it. The question was worded as follows: "Universities are in the situation in which almost all teaching and learning is carried out online. Describe your experiences of the effect of the pandemic on leading teaching".

\subsection{Analysis}

In order to examine the variety of degree programmes directors' experiences, we used open-ended questions and analysed them by content analysis [26]. In the first phase, the descriptions were analysed in an iterative manner, reading them through repeatedly to identify the various experiences. The authors read and analysed descriptions first independently, and formed dimensions of the experiences. Then, the authors compared the dimensions which they found. Both authors identified similar dimensions. 


\section{Results}

The analysis revealed differences between degree programme directors' experiences on educational leadership during the pandemic. The experiences could be divided into seven dimensions, which represented negative, positive and neutral experiences. The dimensions of negative experiences were Lack of interaction, Worry about the situation, and Workload in leading. The dimensions of positive experiences were Increase in online teaching, Flexibility of teaching and learning, and Effective meetings. In addition, some directors considered that the pandemic had not influenced their work. These experiences were categorised as neutral experiences. The experiences are presented in Table 1.

Table 1. Experiences of learning teaching during pandemic and frequencies of all the dimensions.

\begin{tabular}{ccc}
\hline Main Dimension and Frequency & Subdimensions & Frequencies \\
\hline Negative experiences & Lack of interaction & 15 \\
26 & Workload in leading & 4 \\
Worry about the situation & 7 \\
Positive experiences & Increase in online teaching & 3 \\
10 & Flexibility of teaching and learning & 2 \\
\hline Neutral 5 & Effective meetings & 5 \\
\hline
\end{tabular}

Most of the experiences were negative, more precisely, there were 26 mentions of the negative effects of the COVID-19 pandemic. Next, these dimensions are presented in detail.

Lack of interaction includes experiences that interaction has decreased between the directors and teachers. Moreover, the teaching has been conducted alone and teachers have been lonely. There has been a lack of face-to-face meetings which in turn has had a negative effect on engagement. The leaders feel that they are in need of feedback from both teachers and students. The interaction has also been formal. Informal and relaxed interaction has diminished, producing a negative influence on the interaction.

The workload in leading consists of descriptions of how the uncertainty of the situation increases the workload in leading. Leaders need to act quickly and find solutions for different problems in a short time. Additionally, the number of online meetings increased.

Worry about the situation arises mainly from the unclear guidelines for leading teaching and learning at the institutional level. The leaders also described that they were concerned about how teachers and students were doing, especially students with experiences of learning difficulties and sense of loneliness in studying.

The positive experiences were also mentioned, but less frequently than the negative experiences (10 mentions). In addition, many of them started with an explanation, e.g., "if there is something positive", "If one must find positive perspectives in this, then ... ". The positive experiences are described in detail below.

The increase in online teaching was mentioned by three leaders. They described how the pandemic brought new ideas into remote teaching and teachers had shared best practices effectively. They were also planning to have more online teaching in the future, and they would maintain good practices in their teaching.

Flexibility of teaching and learning was considered to be especially beneficial for the students living in other cities and having a long distance to the university. Some leaders thought that there was also a slight increase in credit points as it was easier to attend the lectures online than face-to-face.

Effective meetings were also mentioned as a positive experience. The leaders described that it had been easy to settle things online but at the same time, innovating new things had been difficult.

Neutral experiences were also mentioned by some leaders. No effect on leading teaching was mentioned by some leaders as they emphasised that the pandemic only had an effect on teachers' and students' activities. 


\section{Discussion}

The aim was to detect the variety of how the academic leaders experienced the leading of teaching and learning during the pandemic in higher education. The results showed that there were more negative than positive experiences. Moreover, there were also experiences of pandemic having had no effect on leading teaching and learning. These different experiences are discussed in detail below.

The previous research by Marshall and his colleagues [25] suggested that during the pandemic, the academic leaders needed the ability to provide clear direction, communicate effectively, work collaboratively and engage in adaptive leadership. In the present study, these activities were the ones that leaders found difficult during the pandemic. It appears that in the middle of a crisis such as a pandemic, it was difficult to see the clear direction and be adaptive, more precisely, act quickly and find solutions for all manner of problems. Although the university supported leaders and provided instruction, they were perceived as unclear by many of the leaders. For example, the information and guidelines concerning the pandemic came from many directions. The university had a team for coronavirus management that followed national and regional guidelines and adjusted these in daily life at the university. In addition, faculties had made their own interpretations and guidelines for their own context. Finally, the study programmes had been considering these broad guidelines and what the guidelines meant, course by course. In practice, this has resulted in actions such as informing students, considerations of how to provide laboratory equipment for students working online and also how courses which cannot be held online in any situation can be arranged in a manner consistent with strict health and security regulations.

The leaders also experienced that the interaction was not successful between leaders, teachers and students during the pandemic. Alternatively, they described that if there was interaction, it has been rather formal. Interaction and collaboration are crucial elements in leading $[27,28]$ and especially during a pandemic [25]. Good collaboration, informal and relaxed, is also important in creating the trust between the leaders, teachers and students [27].

The leaders in the present study were concerned about the effect of the pandemic on students' and teachers' wellbeing. In their descriptions, the leaders mentioned their concern about students being left alone. The loss of the university as a community has been found to induce stress, especially among students [29]. Moreover, worrying about students with difficulties in learning seems to be justified, as especially students with a fragmented knowledge base and difficulties in time and effort management have been found to struggle with online teaching during the COVID-19 pandemic [30].

The increase in online teaching was considered to be a positive experience. The leaders emphasised that there will be a need to have more online teaching in the future. However, although technology related to teaching has been essential in enabling teaching during the pandemic, it must be remembered that the digital learning environment will not solve the challenges faced in future learning. With regards to quality learning, the digital learning environment should provide alternative teaching practices for teachers and motivating elements for the students' learning [31-33]. In addition, after the pandemic, the use of technology will not be only for surviving the situation, but it should be part of sustainable and high-quality higher education. This also raises the requirements for leaders to understand digital learning and teaching in higher education.

Interestingly, some leaders experienced that the pandemic had no effect on how they have been leading teaching and learning in their programme. There might be several reasons for these experiences. These descriptions could arise from the situation in which leaders are struggling to balance their managerial and academic tasks [34], as well as finding it difficult to see what is required in leading teaching. These descriptions also highlight that the leaders should have enough training and support in taking care and being aware of their various duties [20]. 


\section{Conclusions}

The present study showed that leading teaching and learning during a pandemic was described mainly by recounting negative experiences. Although there were some mentions of positive effects, they were usually linked to the negative descriptions. The study thus confirms that combining a digital learning environment and leading high-quality teaching and learning has been a challenge during the pandemic [23]. The most important finding of the present study is that the skills that Marshall and his colleagues [25] argue to be important in leading teaching during the pandemic are the ones that the leaders find difficult during the crisis situation of the pandemic. Moreover, these skills will be as important in the future as even when the COVID-19 pandemic is over, the academic leaders will most likely face a new kind of normal.

It must be, however, kept in mind that the use of open-ended answers in a single higher education context only gives us a limited understanding of the phenomenon, and, therefore, this limits the generalisability of the findings to other universities and contexts. In order to examine the whole range of leaders' experiences the use of, for example, in-depth interviews would be useful. It would also be important to gather longitudinal data from the leaders to follow their experiences of the pandemic. That would give more in-depth knowledge and ideas on what we have learned from the crisis situation and what we would like to keep and develop further.

The pandemic has been an exceptional experience, but we can assume that in the future there will be need for online learning and teaching even more than before the pandemic. Online learning environments require a different set of competencies in leading teaching. Students are used to learning online and teachers with only online courses will not adjust easily to the old and traditional university classroom teaching. It is time to move towards harmonious integration of physical and digital teaching, which support active and meaningful learning [35]. The whole community will face challenges in creating a shared sense of community and everyday campus life when the community is segregated between online and on-campus learning. In order to maintain the values of the workplace and pedagogical needs, there must be a lot of communication and collaboration between the leaders, academic staff and students to be able to integrate pedagogy to designing learning spaces and environments [36].

To sum up, higher education leaders need more guidance and training to face crisis situations and develop especially those skills that are related to effective communication. At the same time, they must be able to communicate collaboratively and in an informal way. Moreover, the problems in effective and collaborative communication may be related to the leaders' individual skills in communication. Therefore, the leaders could, for example, have training in transformational leadership, and, especially, in how to encourage withinteam communication, which has been shown to promote the formation of trust in the team, as well as team performance [27]. In a crisis situation, such as a pandemic, they also need to be able to cope with concerns about the academic staff and students and simultaneously to be adaptive, more precisely, to be able to act quickly and find solutions to all types of problem. Thus, they need support in developing adaptive coping strategies for negative emotions, such as self-management (planning, keeping routines, exercise etc.) and support in being a mindful leader with an ability to listen and respond with compassion [37], as well as a supportive network, which has been found to be helpful among higher education students [38]. Leaders must be ready to construct the kind of culture of confidential interaction that enables the whole community to create safe, creative and responsible learning environments, both online and on campus.

Author Contributions: Conceptualisation, A.P. and S.N.-S.; methodology, A.P and S.N.-S.; validation, A.P. and S.N.-S.; formal analysis, A.P. and S.N.-S.; data curation, A.P.; writing-original draft preparation, A.P. and S.N.-S.; writing-review and editing, A.P. and S.N.-S.; project administration, A.P. All authors have read and agreed to the published version of the manuscript.

Funding: Open access funding provided by University of Helsinki. 
Institutional Review Board Statement: This study followed the ethical principles of research with human participants and ethical review in the human sciences in Finland (Finnish National Bord on Research Integrity TENK guidelines 2019).

Informed Consent Statement: Informed consent was obtained from all subjects involved in the study.

Data Availability Statement: The data that support the findings of this study are available on request from the corresponding author (A.P.) upon reasonable request.

Conflicts of Interest: The authors declare no conflict of interest.

\section{References}

1. Marioni, G.; Van'tland, H.; Jensen, T. The Impact of COVID-19 on higher education around the world: IAU Global Survey Report 2020. Available online: https://www.iauaiunet/IMG/pdf/iau_covid19_and_he_survey_report_final_may_2020.pdf (accessed on 12 December 2021)

2. Petillion, R.J.; McNeil, W.S. Student experiences of emergency remote teaching: Impacts of instructor practice on student learning, engagement, and well-being. J. Chem. Educ. 2020, 97, 2486-2493. [CrossRef]

3. Aguilera-Hermida, A.P. College students' use and acceptance of emergency online learning due to COVID-19. IJEDRO 2020, 1, 100011. [CrossRef] [PubMed]

4. Daniels, L.M.; Goegan, L.D.; Parker, P.C. The impact of COVID-19 triggered changes to instruction and assessment on university students' self-reported motivation, engagement and perceptions. Soc. Psychol. Educ. 2021, 24, 299-318. [CrossRef]

5. Haikalis, M.; Doucette, H.; Meisel, M.K.; Birch, K.; Barnett, N.P. Changes in College Student Anxiety and Depression From Pre-to During-COVID-19: Perceived Stress, Academic Challenges, Loneliness, and Positive Perceptions. Emerg. Adulthood. 2021, 1-12. [CrossRef]

6. Damşa, C.; Langford, M.; Uehara, D.; Scherer, R. Teachers' agency and online education in times of crisis. Comput. Hum. Behav. 2021, 121, 106793. [CrossRef]

7. Scherer, R.; Howard, S.K.; Tondeur, J.; Siddiq, F. Profiling teachers' readiness for online teaching and learning in higher education: Who's ready? Comput. Hum. Behav. 2021, 118, 106675. [CrossRef]

8. Meishar-Tal, H.; Levenberg, A. In times of trouble: Higher education lecturers' emotional reaction to online instruction during COVID-19 outbreak. Educ. Inf. Technol. 2021, 26, 7145-7161. [CrossRef]

9. Bdair, I. Nursing students' and faculty members' perspectives about online learning during COVID-19 pandemic: A qualitative study. Teach. Learn. Nurs. 2021, 16, 220-226. [CrossRef]

10. Iglesias-Pradas, S.; Hernández-García, Á.; Chaparro-Peláez, J.; Prieto, J.L. Emergency remote teaching and students' academic performance in higher education during the COVID-19 pandemic: A case study. Comput. Hum. Behav. 2021, 119, 106713 [CrossRef]

11. Coman, C.; Tîru, L.G.; Meseșan-Schmitz, L.; Stanciu, C.; Bularca, M.C. Online teaching and learning in higher education during the coronavirus pandemic: Students' perspective. Sustainability 2020, 12, 10367. [CrossRef]

12. Dubey, P.; Pandey, D. Distance learning in higher education during pandemic: Challenges and opportunities. Int. J. Ind. Psychol 2020, 8, 43-46.

13. Oliveira, G.; Grenha Teixeira, J.; Torres, A.; Morais, C. An exploratory study on the emergency remote education experience of higher education students and teachers during the COVID-19 pandemic. Br. J. Educ. Technol. 2021, 52, 1357-1376. [CrossRef]

14. Gunsalus, C.K. The College Administrator's Survival Guide: Revised Edition. Available online: https://www.perlego.com/ book/1133047/the-college-administrators-survival-guide-pdf (accessed on 12 December 2021).

15. Buller, J.L. Change Leadership in Higher Education: A Practical Guide to Academic Transformation; John Wiley \& Sons: San Francisco, CA, USA, 2014

16. Kruse, S.D.; Hackmann, D.G.; Lindle, J.C. Academic Leadership During a Pandemic: Department Heads Leading with a Focus on Equity. Front. Educ. 2020, 5, 614641. [CrossRef]

17. Gurr, D.; Drysdale, L. Leadership for challenging times. ISEA 2020, 48, 24-31.

18. Schloss, P.J.; Cragg, K.M. Organization and Administration in Higher Education; Routledge: New York, NY, USA, 2013.

19. Quinlan, K. Leadership of teaching for student learning in higher education: What is needed? High. Educ. Res. Dev. 2014, 33, 32-45. [CrossRef]

20. Cipriano, R.E. Facilitating a Collegial Department in Higher Education: Strategies for Success; John Wiley \& Sons: San Francisco, CA, USA, 2011; Volume 130.

21. Tucker, A. Chairing the Academic Department: Leadership Among Peers; ACE/MacMillan: New York, NY, USA, 1984.

22. Gmelch, W.H.; Roberts, D.; Ward, K.; Hirsch, S. A retrospective view of department chairs: Lessons learned. Dep. Chair 2017, 28, 1-4. [CrossRef]

23. Jahagirdar, S.; Chatterjee, A.; Behera, S.; Mohapatra, A. Response to the COVID-19 pandemic in India: Case studies on leadership in crisis situations. Int. J. Health Allied Sci. 2020, 9, 81-84.

24. Gurr, D. Educational Leadership and the Pandemic. Acad. Lett. 2020, 29, 1-6. [CrossRef] 
25. Marshall, J.; Roache, D.; Moody-Marshall, R. Crisis leadership: A critical examination of educational leadership in higher education in the midst of the COVID-19 pandemic. ISEA-CCEAM 2020, 48, 30-37.

26. Flick, U. Qualitative research-state of the art. Soc. Sci. Inf. 2002, 41, 5-24. [CrossRef]

27. Boies, K.; Fiset, J.; Harjinder, G. Communication and trust are key: Unlocking the relationship between leadership and team performance and creativity. Leadersh. Q. 2015, 26, 1080-1094. [CrossRef]

28. De Vries, R.E.; Bakker-Pieper, A.; Oostenveld, W. Leadership = Communication? The relations of Leaders'Communication Styles with Leadership Styles, Knowledge, Sharing and Leadership Outcomes. J. Bus. Psychol. 2010, 25, 367-380. [CrossRef] [PubMed]

29. Sangster, A.; Stoner, G.; Flood, B. Insights into accounting education in a COVID-19 world. Account. Educ. 2020, $29,431-562$. [CrossRef]

30. Parpala, A.; Katajavuori, N.; Haarala-Muhonen, A.; Asikainen, H. How Did Students with Different Learning Profiles Experience 'Normal' and Online Teaching Situation during COVID-19 Spring? Soc. Sci. 2021, 10, 337. [CrossRef]

31. Stephan, M.; Markus, S.; Gläser-Zikuda, M. Students' Achievement Emotions and Online Learning in Teacher Education. Front. Educ. 2019, 4, 109. [CrossRef]

32. Wortha, F.; Azevedo, R.; Taub, M.; Narciss, S. Multiple Negative Emotions during Learning With Digital Learning EnvironmentsEvidence on Their Detrimental Effect on Learning From Two Methodological Approaches. Front. Psychol. 2019, $10,2678$. [CrossRef]

33. Knox, J. Digital culture clash: "massive" education in the E-learning and Digital Cultures MOOC. Distance Educ. 2014, 35, 164-177. [CrossRef]

34. Smith, R. The role of the university head of department: A survey of two British universities. Educ. Manag. Adm. 2002, 30, 293-312. [CrossRef]

35. Rapanta, C.; Botturi, L.; Goodyear, P.; Guàrdia, L.; Koole, M. Balancing technology, pedagogy and the new normal: Post-pandemic challenges for higher education. Postdigit. Sci. Educ. 2021, 3, 715-742. [CrossRef]

36. Sandström, N.; Nevgi, A. From needs to deeds: Where is pedagogy in changing the working and learning environments on a university campus? J. Corp. Real Estate 2019, 22, 1-20. [CrossRef]

37. McNamara, A. Crisis Management in Higher Education in the Time of COVID-19: The Case of Actor Training. Educ. Sci. 2021, 11, 132. [CrossRef]

38. Son, C.; Hegde, S.; Smith, A.; Wang, X.; Sasangohar, F. Effects of COVID-19 on college students' mental health in the United States: Interview survey study. J. Med. Internet Res. 2020, 22, e21279. [CrossRef] [PubMed] 